\title{
Vocal traits of shorebird chicks are related to body mass and
}

\section{$\operatorname{sex}$}

Kristal N. Kostoglou ${ }^{1 *}$, Edward H. Miller ${ }^{2}$, Michael A. Weston ${ }^{1}$ and David R. Wilson ${ }^{3}$

${ }^{1}$ Deakin University, Geelong, Australia. School of Life and Environmental Sciences, Deakin University, Burwood Campus, 221 Burwood Highway, Burwood, VIC, 3125, Australia, knko@deakin.edu.au*

${ }^{2}$ Biology Department, Memorial University, St. John's NL, Canada

${ }^{3}$ Psychology Department, Memorial University, St. John's NL, Canada

* Corresponding author: knko@deakin.edu.au, +61416423182 


\section{Vocal traits of shorebird chicks are related to body mass and}

\section{$\operatorname{sex}$}

Acoustic communication is critical during early life phases in precocial birds. For example, adult alarm calls can elicit antipredator behaviour in young, and chick vocalisations can communicate information to parents about chick identity, condition, location, sex, or age. We investigated whether chick calls of two species of Australian Charadriidae vary with sex or body mass. We handled Red-capped Plover Charadrius ruficapillus and Southern Masked Lapwing Vanellus miles novaehollandiae chicks for purposes of measurement, blood sampling, and banding. We opportunistically recorded their distress calls while in the hand, and analysed the calls to determine whether call structure is related to sex or body mass (a proxy for age). We measured five traits per call, plus time intervals between successive calls, for 26 plover chicks ( 2600 calls) and 95 lapwing chicks (6835 calls). In plovers, inter-call intervals were shorter in males and both inter-call interval and the dominant frequency range of calls decreased with increasing body mass. In lapwings, frequency modulation (computed as the range in the rate of change of the dominant frequency) was lower in male calls. The dominant frequency range of lapwing calls decreased with mass in both sexes, but the decline was greater in males, resulting in a lower dominant frequency range in males. Frequency modulation and entropy of lapwing calls also decreased with increasing body mass. Minimum dominant frequency did not change with body mass or sex in either species. Our study provides the first evidence for charadriid chicks of (a) a sexual difference in call structure and rate and (b) gradual growth-related changes in call structure and rate, across chicks. Studies on calls from a 
greater range of chick ages and from more species within this large and diverse family would be valuable. We provide a foundation for further studies of shorebird vocalisations during growth, which may elucidate the development and functional significance of such vocalisations.

\section{Keywords}

body growth, Charadrius ruficapillus, distress call, sexual difference, Vanellus miles novaehollandiae, vocal development 
Acoustic communication can be critical in the early life of birds. In nestlings, begging calls can solicit parental feeding, contact calls can help parents locate and identify offspring, and distress calls given during social separation, environmental challenges, or handling can startle predators or elicit help from parents, conspecifics, or other nearby species (Stefanski and Falls 1972, Sethi et al. 2012). Several studies have investigated the function of calls in juvenile birds (e.g. Desmedt et al. 2020) but few have considered the structure or development of juvenile calls. Developmental changes in chick vocalisations can allow parents to assess chick condition (e.g. Goedert et al. 2014) and have been documented for some precocial species (e.g. Würdinger 1970, Desmedt et al. 2020). With some exceptions (Herting and Belthoff 2001, Odom and Mennill 2010), there is a general trend for the dominant frequency of calls to be inversely related to body mass or size across species, possibly due to the greater mass of vocal structures or respiratory muscles (Suther and Zollinger 2004). Larger birds also may be constrained in producing higher frequencies (e.g., via stronger constraints on tissue elasticity with larger anatomical structures; Demery et al. 2021). Intraspecifically, changes in vocalisations can occur gradually as body mass increases with age (Dragonetti et al. 2013), or in a steplike fashion (Klenova et al. 2014).

Vocal traits also can differ between sexes, and play important roles in reproduction, territorial defence, and other social activities (Buck et al. 2021). Sexual differences emerge at various times during development in different species, from several days old to after fledging (Cosens 1981, Saino et al. 2008) to as late as at sexual maturity (Klenova et al. 2014), but no general patterns are evident (Tikhonov 1986, ten Thoren and Bergmann 1987a,b, Volodin et al. 2015). The nature of sexual differences in calls also 
varies across species, for example, in the dominant frequency (ten Thoren and Bergmann 1987a), duration (Tikhonov 1986), or amplitude (Saino et al. 2008) of calls. Some interspecific variation in the occurrence and nature of sex-related differences may result from patterns of growth, sexual differences in body size, or ecological or social factors (Saino et al. 2003, Volodin et al. 2015, Austin et al. 2021).

Vocal communication in shorebirds can help keep precocial young close to their parents and away from predators, and might also play a role in mediating sexual differences in the survival, parental care, and dispersal of young (Pakanen et al. 2015, Eberhart-Phillips et al. 2017, Lees et al. 2018, 2019). However, despite a plethora of studies and reviews on social organisation, breeding biology, behavioural ecology, and communication in shorebirds, vocal development has been examined in only two species. Adret (2012) quantified age-related changes in measures of call frequency and noted a sexual difference in call rates for Pied Avocet Recurvirostra avosetta chicks. Dragonetti et al. (2013) described qualitative changes of Eurasian Stone-curlew Burhinus oedicnemus chick calls with age. To extend knowledge of vocal communication and development in shorebirds, we investigated potential relationships of call traits to body mass and sex in chicks of two shorebird species. When in the hand for banding and blood sampling, chicks of Red-capped Plover Charadrius ruficapillus and Southern Masked Lapwing Vanellus miles novaehollandiae ("plovers" and "lapwings" hereafter) often utter distress calls. We recorded these calls to document their structure (Miller et al. 2021), and to determine whether they change with body mass (a proxy for age) or differ between sexes. We predicted that call structure, especially frequency-related characteristics, would change with increasing body mass (Demery et al. 2021). In some precocial bird species, it would 
likely be beneficial for parents to distinguish the sex of their offspring, for purposes of parental defence and care (Barrios-Miller and Siefferman 2013, Lees et al. 2018). We therefore predicted sexual differences in chick calls. Our study provides the first account of call development for any species of Charadriidae.

\section{Methods}

We studied plovers from October 2017 to March 2018 (Cheetham Wetlands, Victoria, Australia; $37^{\circ} 54^{\prime} \mathrm{S} 144^{\circ} 47^{\prime} \mathrm{E} ; 420$ ha). Male chicks have slightly longer tarsi than females (Lees et al. 2019), but otherwise the sexes are indistinguishable until their second immature plumage (Marchant and Higgins 1993). We studied lapwings, which have sexually indistinguishable young (Lees et al. 2018), from June to September 2018 (Phillip Island, Victoria, Australia; $38^{\circ} 29^{\prime} \mathrm{S}, 145^{\circ} 14^{\prime} \mathrm{E}$; 10,000 ha). Parents brood and defend their chicks which attain the capacity for sustained flight at approximately 35 (plovers) and 45 (lapwings) days of age (Temple-Smith 1969, Marchant and Higgins 1993, Lees et al. 2018).

We conducted extensive searches for nests from vehicles and by foot. Upon discovering a nest, we estimated approximate hatching dates by floating the eggs (Liebezeit et al. 2007), assuming incubation periods of 30 days (plovers) and 32 days (lapwings) (Marchant and Higgins 1993, Lees et al. 2018). We returned to nests around our estimated hatching dates to capture chicks. Occasionally, we captured older unbanded chicks away from known nests. For each captured chick, we measured body mass (Pesola spring balance: $\pm 0.1 \mathrm{~g}$ ), and tarsus, tarsus plus toe, culmen, and head plus culmen lengths (dial calliper: $\pm 0.1 \mathrm{~mm}$ ) (Rogers et al. 1990). All body measurements are 
provided within Supporting Information Tables S1 and S2. We use only body mass as a proxy for age because: 1) we did not know exact ages of most chicks, 2) all variables describing body size were highly inter-correlated ( $r$ Pearson $\geq 0.75$ for all pairwise combinations), and 3) a relationship of call structure to body mass occurs in other species (Martin et al. 2011). We also obtained ca. $50 \mu \mathrm{L}$ of blood from the tarsal vein of each chick, which permitted genetic sexing (DNA Solutions ${ }^{T M}$ ). We recaptured and measured (excluding blood extraction) five plover chicks (mean interval between captures: $8.6 \pm 3.4$ days, range: $6-14$ days, $n=5$ ) but did not recapture any lapwing chicks. We cite mean \pm SD throughout.

\section{Call recording and acoustic analysis}

We processed chicks singly (plover: $9.8 \pm 5.1$ minutes, $n=26$; lapwings: $5.7 \pm 2.9, n=$ 95) in a quiet, sheltered location. We recorded their vocalisations using a portable digital recorder (Roland R-26, WAVE format, $44.1 \mathrm{kHz}$ sampling rate, and 16-bit depth) and an omni-directional Sennheiser ME 2-II microphone (50-18,000 Hz frequency response) held approximately $5 \mathrm{~cm}$ from the chick. Recordings sometimes included calls of siblings held nearby, but these calls were distinguishable in our recordings; we assume they do not influence the variables we measure. For the five plover chicks that were recaptured, we analysed vocalisations from their second capture.

We provide a detailed account of acoustic analysis in Supplemental Methods. Briefly, after filtering calls, we identified start and end times of each call and we divided each call into a series of contiguous 2.9-ms time bins. We measured the Shannon spectral entropy and dominant frequency from a mean power spectrum for each bin. We used six call traits 
for analyses: (1) call duration, the time interval between the start and end of a call (seconds); (2) inter-call interval (ICI), the interval between the end of a call and the start of the next (seconds); (3) entropy, the average of all spectral entropy values within a call (unitless); (4) minimum dominant frequency $(\mathrm{kHz})$; (5) dominant frequency range, the difference between a call's minimum and maximum dominant frequency $(\mathrm{kHz})$; and (6) frequency modulation. For lapwings, we calculated frequency modulation by fitting a series of polynomial regressions (up to twelfth order) to the dominant frequency and time values of the call, selecting the best-fitting model (Supporting Information Fig. S1). For each 2.9-ms time bin, we calculated the slope of the tangent to the polynomial curve and used the range of slopes across the call as our measure of frequency modulation (kHz/s) (Supporting Information Fig. S1). For plovers, polynomial regression curves could not adequately model the frequency modulations. Instead, we defined frequency modulation as the cumulative absolute change in dominant frequency across all 2.9-ms time bins, divided by call duration $(\mathrm{kHz} / \mathrm{s})$. We also calculated maximum dominant frequency as a separate variable, but excluded it because it was highly correlated with dominant frequency range for both species ( $r_{\text {Pearson }}=0.86$ and 0.89 for plovers and lapwings, respectively) and because statistical models exhibited poor fit (see below). Correlations among the remaining six variables were all $<0.7$. Not all variables could be calculated from every call.

\section{Statistical analysis}

Separate generalised linear mixed models (GLMMs) examined possible relationships among call traits, body mass and sex for each species. We included chick identity nested 
within brood identity as a random effect to account for possible dependencies among calls recorded from the same chick or brood. We specified a Toeplitz covariance structure (Glaz and Yeater 2020) to account for sequential autocorrelation between calls. We included body mass and sex as main effects in all models. For some traits, an interactive effect between body mass and sex might occur, although we had no a priori reason to expect this. Nevertheless, for each analysis, we compared a model with main effects only to a model with main effects plus an interaction term between body mass and sex. We based model selection on the Akaike Information Criterion (AIC) values, with best models being identified where they differed from the alternative candidate model by $\Delta \mathrm{AIC}>2$ (Symonds and Moussalli 2011). Where candidate models appeared to be equally informative $(\triangle A I C \leq 2)$, we did not include the interaction term in the final model (the maineffects-only model always had the lowest AIC).

We tested model assumptions and evaluated model fit by comparing observed data to simulated data derived from the model (Hartig 2018). For lapwings, many calls had a measured frequency modulation of zero, which resulted in poor model fit (i.e. outliers had significant leverage) that could not be improved through the use of zero-inflated models (Brooks et al. 2017). We retained the zeros within the final model because they were not errors, and their removal did not change the results with respect to statistical significance (Supporting Information Fig. S2 and Table S3). When analysing entropy, we excluded calls for which the recording was saturated (the input of a signal was greater than the output, creating clipping and distortion to the shape of the waveforms; plovers, $n=939$ calls; lapwings, $n=3647$ ). Saturation can affect entropy, and the entropy differed significantly between saturated and non-saturated calls (Supporting Information Table 
S4). When analysing ICls, we excluded recordings with $<10$ calls (plovers, $n=3$ recordings; lapwings, $n=20$ ) because calling was too sporadic to get a reliable measure of ICI. We used the median ICI of each individual's recording (excluding any sibling calls), since we had no objective way of distinguishing calling bouts.

Transformations of data were performed to improve distribution and model fit. We applied a reciprocal transformation on body mass for both species for all models. For lapwings, we added a constant (i.e. 2) and then logarithmically transformed the data for frequency modulation, dominant frequency range, and $\mathrm{ICI}$. We performed the same transformation for dominant frequency range and ICI for plovers; however, as entropy was left-skewed, we subtracted values from a constant (2) and then log-transformed the data. We indicate probability distributions and link functions within the tables.

We performed analyses in $\mathrm{R}$ using the glmmTMB package for running mixed models, DHARMa for model assumption testing, bbmle for calculating $\triangle \mathrm{AIC}$ values, psych for creating histograms and scatterplots, base $\mathrm{R}$ for creating and observing simulated data and ggplot2 and ggeffects for figures (Wickham 2016, Brooks et al. 2017, Hartig 2018, Lüdecke 2018, Bolker and R Core Team 2020, 2021, Revelle 2021). We controlled the experiment-wise type I error rate by applying a Bonferroni correction, which adjusted our alpha value from 0.05 to 0.0083 . For figures, ICls, entropy, and dominant frequency range were back-transformed and presented on the original scale in figures. Estimated marginal means (hatched and solid lines) and 95\% confidence intervals (grey shading) were calculated using ggeffects (Lüdecke 2018). 


\section{Results}

For plovers, we recorded 2600 vocalisations from 26 individual chicks (1-248 calls per chick; 570 calls from 9 females and 2030 calls from 17 males), over the body mass range of $3.5-20.5 \mathrm{~g}(8.5 \pm 4.6 \mathrm{~g})$. This range corresponds to chick ages from the day of hatching to approximately 4 weeks of age (Lees et al. 2019).

For lapwings, we recorded 6835 vocalisations from 95 individual chicks (1-336 calls per chick; 3174 calls from 46 females and 3661 calls from 49 males), over the body mass range of $15.2-177.0 \mathrm{~g}(43.6 \pm 30.2 \mathrm{~g})$. This range corresponds to chick ages from the day of hatching to approximately 5 weeks of age (Thomas 1969, Moffat 1981).

For plovers, ICls were shorter for males than for females and, as mass increased, ICls and the dominant frequency range of calls decreased (Table 1, Fig. 1). There were no significant relationships of call duration, entropy, minimum dominant frequency, or frequency modulation to sex or body mass.

For lapwings, frequency modulation was lower for males than for females (Table 1, Fig. 2). For both sexes, dominant frequency range decreased with increasing body mass; however, the decline was greater in males, resulting in a lower dominant frequency range than for females (Table 1; Fig. 2). As body mass increased, frequency modulation and entropy of lapwing calls decreased (Table 1; Fig. 2). Call duration, minimum dominant frequency and $\mathrm{ICI}$ were not predicted by sex or body mass.

\section{Discussion}


Multiple call traits were associated with body mass; vocal traits changed gradually, as has been described previously in growing shorebirds (Adret 2012, Dragonetti et al. 2013), although repeated measurements of the same individuals are required to confirm this. For both study species, minimum dominant frequency was not associated with body mass, whereas dominant frequency range decreased with increasing body mass, consistent with maximum dominant frequency declining over growth in birds (Würdinger 1970, Adret 2012, Dragonetti et al. 2013). The decline in frequency modulation with increasing body mass in lapwings (and a similar but non-significant pattern for plovers) is consistent with the idea that frequency fluctuations within a call decrease with growth. Large bill size may impede the ability to quickly open and close the bill, therefore limiting the rate of frequency modulation (Podos 2001, Demery et al. 2021), though other explanations exist. Shorter ICls were associated with heavier body masses in plovers, which might reflect the capacity of older, heavier, chicks to control airflow through vocal structures (Franz and Goller 2002, Zvonov 2011). We did not detect a change in call duration with age in either species (but see Adret 2012). Heavier lapwing chicks produced calls that were more tonal (i.e. reduced entropy), possibly associated with increased motor control of the upper vocal tract (Podos et al. 1995). As chicks age, variation in call structure may reflect attempts to utter adult-like calls, as described for other shorebirds (Adret 2012, Dragonetti et al. 2013).

For lapwings, frequency modulation was higher in females and, for plovers, male chicks had higher call rates than females. Compared to females, male Red-capped Plover chicks had shorter ICls from hatching; cooing rates were also higher in male Pied Avocet chicks until the age of 9 months (Adret 2012). A faster repetition rate of distress calling might 
increase response intensity by adult defenders (Wheatcroft 2015), which could contribute to the higher survival of male over female chicks reported for several plover species (Sandercock et al. 2005, Pakanen et al. 2015, Saunders and Cuthbert 2015, EberhartPhillips et al. 2017; but see Lees et al. 2019). For lapwings, dominant frequency range declined with body mass more in males than in females, resulting in the development of a lower overall dominant frequency range in males. Frequency modulation was also lower in males than in females from hatching and throughout growth, suggesting differences in calls between the sexes at hatching. The sexes may differ in the size or rate of development in vocal anatomy, or the vocal control of these structures (Ballintijn and ten Cate 1997a, Gahr 2007, Volodin et al. 2015).

Overall, calls between the sexes were similar in most respects. Contextually, this study analysed distress calls (loud, harsh, and locatable; Sethi et al. 2012), which are likely under the influence of natural selection (Martin et al. 2011). Some non-distress vocalisations (e.g. contact calls) might communicate the caller's sex, whereas distress calls may not (Austin et al. 2021). Even when a sex is "preferred" by parents, calls of the non-preferred sex are expected to evolve to be similar to those of the preferred sex (Austin et al. 2021). Furthermore, distress calls emitted by chicks may serve to communicate with siblings, other conspecifics, the predator, or some combination of these. Future studies should therefore investigate associations between shorebird chick calls and sex using the full repertoire of chick calls, and across species whose adult call repertoires and characteristics vary between sexes. We note our limited sample size, bias toward young chicks, and imbalance in sex ratio for plovers (34.6\% were female) and suggest further study would be desirable. We also note that we did not repeatedly 
measure the same individuals, so cannot unambiguously exclude effects such as those associated with survival bias.

This research complies with the current laws of Australia and was conducted in accordance with protocols reviewed and approved by the Deakin University Animal Ethics Committee (Permit numbers B01 2018, B11 2017 and B12 2017) and the Department of Environment, Land, Water and Planning (Permits 10008437 and 10008619). The authors minimised impacts on chicks by only collecting data on days of suitable weather (e.g. no rain or extreme heat) and by generally avoiding recaptures. This project was supported by The Holsworth Wildlife Research Endowment and The Ecological Society of Australia. MAW was supported during write-up by the Beach Ecology and Conservation Hub (BEACH, Venus Bay). Thanks to Dr Peter Dann (Phillip Island Nature Parks) and Rangers at the Point Cook Coastal Park (Ron Cuthbert, Russell

Brooks, Mark Cullen and Bernie McCarrick) for their assistance, to Ekaterina Ershova for her help in translating Russian material and to Rachel Adams (UTas) for bibliographic help.

\section{Author contributions}

Methodology, K.N.K., M.A.W., D.R.W. and E.H.M.; Investigation, K.N.K.; Formal Analysis, K.N.K., D.R.W. and E.H.M.; Writing - Original Draft, K.N.K.; Writing - Review and Editing, K.N.K., M.A.W., D.R.W. and E.H.M.; Funding Acquisition, K.N.K.; Supervision, M.A.W.

\section{Data availability statement}

The datasets generated during and/or analysed during the current study are available in the figshare repository via: $10.6084 / \mathrm{m} 9$. figshare. 14813379 


\section{REFERENCES}

Adret, P. 2012. Call development in captive-reared Pied Avocets, Recurvirostra avosetta. -J. Ornithol., 153: 535-546.

Austin, V. I., Dalziell, A. H., Langmore, N. E. and Welbergen, J. A. 2021. Avian vocalisations: The female perspective. -Biol Rev., https://doi.org/10.1111/brv.12713

Ballintijn, M. R. and ten Cate, C. 1997a. Sex differences in the vocalizations and syrinx of the Collared Dove (Streptopelia decaocto). -Auk, 114: 22-39.

Ballintijn, M. R. and ten Cate, C. 1997b. Vocal development and its differentiation in a non-songbird: The Collared Dove (Streptopelia decaocto). -Behaviour, 134: 595621.

Barrios-Miller, N. L. and Siefferman, L. 2013. Evidence that fathers, but not mothers, respond to mate and offspring coloration by favouring high-quality offspring. -Anim. Behav., 85: 1377-1383.

Bolker, B. and R Core Team. 2020. bbmle: Tools for general maximum likelihood $\begin{array}{lllll}\text { estimation. } & R & \text { package version 1.0.23.1. https://CRAN.R- }\end{array}$ project.org/package $=$ bbmle

Brooks, M. E., Kristensen, K., van Benthem, K. J., Magnusson, A., Berg, C. W., Nielsen, A., Skaug, H. J., Maechler, M. and Bolker, B. M. 2017. GlmmTMB balances speed and flexibility among packages for zero-inflated generalized linear mixed modeling.-R J., 9: 378-400.

Buck, E. J., Brown, T., Zwicky, G., Derryberry, E. P. and Lipshutz, S. E. 2021. Species and sex differences in vocalizations between sex-role reversed shorebirds, 
Northern Jacana (Jacana spinosa) and Wattled Jacana (J. jacana). - Wilson J. Ornithol., 132: 343-351.

Cosens, S. E. 1981. Development of vocalizations in the American Coot. -Can. J. Zool., 59: 1921-1928.

Demery, A.-J. C., Burns, K. J. and Mason, N. A. 2021. Bill size, bill shape, and body size constrain bird song evolution on a macroevolutionary scale. -Ornithology, 138: 111.

Desmedt, L., George, I., Mohamed Benkada, A., Hervé, M., Aubin, T., Derégnaucourt, S. and Lumineau, S. 2020. Maternal presence influences vocal development in the Japanese Quail (Coturnix c. japonica). -Ethology, 126: 553-562.

Dragonetti, M., Caccamo, C., Corsi, F., Farsi, F., Giovacchini, P., Pollonara, E. and Giunchi, D. 2013. The vocal repertoire of the Eurasian Stone-curlew (Burhinus oedicnemus). - Wilson J. Ornithol., 125: 34-49.

Duckworth, A., Masello, J. F., Mundry, R. and Quillfeldt, P. 2009. Functional characterization of begging calls in Thin-billed Prions Pachyptila belcheri chicks. Acta Ornithol., 44: 127-137.

Eberhart-Phillips, L. J., Küpper, C., Miller, T. E., Cruz-López, M., Maher, K. H., Dos Remedios, N., Stoffel, M. A., Hoffman, J. I., Krüger, O. and Székely, T. 2017. Sexspecific early survival drives adult sex ratio bias in Snowy Plovers and impacts mating system and population growth. - Proc. Natl. Acad. Sci. U.S.A., 114: E5474E5481.

Franz, M. and Goller, F. 2002. Respiratory units of motor production and song imitation in the Zebra Finch. -J. Neurobiol., 51: 129-141. 
Gahr, M. 2007. Sexual differentiation of the vocal control system of birds. In: Yamomoto D. (ed.) Genetics of sexual differentiation and sexually dimorphic behaviors. Advances in Genetics, vol. 59. Elsevier, Amsterdam, The Netherlands, pp. 67-105.

Glaz, B. and Yeater, K. M. 2020. Applied statistics in agricultural, biological, and environmental sciences - American Society of Agronomy, Madison, WI, USA.

Goedert, D., Dias, R. I. and Macedo, R. H. 2014. Nestling use of alternative acoustic antipredator responses is related to immune condition and social context. -Anim. Behav., 91: 161-169.

Hartig, F. 2018. DHARMa: Residual diagnostics for hierarchical (multi-level/mixed) regression models. $R$ package version 0.4.1. https://CRAN.Rproject.org/package=DHARMa

Herting, B. L., Belthoff, J. R. and Kroodsma, D. 2001. Bounce and double trill songs of male and female Western Screech-owls: Characterization and usefulness for classification of sex. -Auk, 118: 1095-1101.

Klenova, A. V., Goncharova, M. V., Bragina, E. V. and Kashentseva, T. A. 2014. Vocal development and voice breaking in Demoiselle Cranes (Anthropoides virgo). Bioacoustics, 23: 247-265.

Lees, D., Schmidt, T., Sherman, C. D. H., Maguire, G. S., Dann, P. and Weston, M. A. 2019. Equitable chick survival in three species of the non-migratory shorebird despite species-specific sexual dimorphism of the young. -Animals, 9: 271-286.

Lees, D., Sherman, C. D. H., Kostoglou, K., Tan, L. X. L., Maguire, G. S., Dann, P. and Weston, M. A. 2018. Plover parents care more for young of the opposite sex. Behav. Ecol., 29: 933-938. 
Liebezeit, J. R., Smith, P. A., Lanctot, R. B., Schekkerman, H., Tulp, I., Kendall, S. J., Tracy, D. M., Rodrigues, R. J., Meltofte, H., Robinson, J. A., Gratto-Trevor, C., Mccaffery, B. J., Morse, J. and Zack, S. W. 2007. Assessing the development of shorebird eggs using the flotation method: Species-specific and generalized regression models. -Condor, 109: 32-47.

Lüdecke, D. 2018. ggeffects: Tidy data frames of marginal effects from regression models. -J. Open Source Softw., 3: 772-777.

Marchant, S. and Higgins, P. J. 1993. Handbook of Australian, New Zealand \& Antarctic birds, volume 2: Raptors to lapwings - Oxford University Press, Melbourne.

Martin, J. P., Doucet, S. M., Knox, R. C. and Mennill, D. J. 2011. Body size correlates negatively with the frequency of distress calls and songs of Neotropical birds. $-J$. Field Ornithol., 82: 259-268.

Miller, E. H., Kostoglou, K. N., Wilson D. R. and Weston, M. A. 2021. Anatomy of avian distress calls: structure, variation, and complexity in two species of shorebird (Aves: Charadrii). Behaviour

Moffat, M. 1981. Aspects of the biology of the Spur-winged Plover (Vanellus miles novaehollandiae Stephens 1819). M.Sc. thesis, Massey University, New Zealand.

Odom, K. J. and Mennill, D. J. 2010. A quantitative description of the vocalizations and vocal activity of the Barred Owl. -Condor, 112: 549-560.

Pakanen, V.-M., Lampila, S., Arppe, H. and Valkama, J. 2015. Estimating sex specific apparent survival and dispersal of Little Ringed Plovers (Charadrius dubius). Ornis Fenn., 92: 172-187. 
Podos, J. 2001. Correlated evolution of morphology and vocal signal structure in Darwin's finches. -Nature, 409: 185-188.

Podos, J., Sherer, J. K., Peters, S. and Nowicki, S. 1995. Ontogeny of vocal tract movements during song production in Song Sparrows. -Anim. Behav., 50: 12871296.

R Core Team 2021. R: A language and environment for statistical computing. $R$ Foundation for Statistical Computing, Vienna. https://www.R-project.org/

Revelle W. 2021. Psych: Procedures for psychological, psychometric, and personality research. Northwestern University, Evanston, Illinois. R package version 2.1.3, https://CRAN.R-project.org/package=psych.

Rogers, K., Rogers, A., Rogers, D., Lane, B. and Male, B. 1990. Bander's aid. Supplement number one. Royal Australasian Ornithologists Union Report No. 67, Melbourne, Australia.

Saino, N., de Ayala, R. M., Boncoraglio, G. and Martinelli, R. 2008. Sex difference in mouth coloration and begging calls of Barn Swallow nestlings. -Anim. Behav., 75: 1375-1382.

Saino, N., Galeotti, P., Sacchi, R., Boncoraglio, G., Martinelli, R. and Møller, A. P. 2003. Sex differences in begging vocalizations of nestling Barn Swallows, Hirundo rustica. -Anim. Behav., 66: 1003-1010.

Sandercock, B. K., Székely, T. and Kosztolányi, A. 2005. The effects of age and sex on the apparent survival of Kentish Plovers breeding in southern Turkey. -Condor, 107: 583-596. 
Saunders, S. P. and Cuthbert, F. J. 2015. Chick mortality leads to male-biased sex ratios in endangered Great Lakes Piping Plovers. -J. Field Ornithol., 86: 103-114.

Sethi, V. K., Bhatt, D. and Kumar, A. 2012. Characteristics and behavioral correlates of call types in a tropical bird, the Pied Bush Chat Saxicola caprata. -Pak. J. Zool., 44: 1231-1238.

Stefanski, R. A. and Falls, J. B. 1972. A study of distress calls of Song, Swamp, and White-throated Sparrows (Aves: Fringillidae). I. Intraspecific responses and functions. -Can. J. Zool., 50: 1501-1512.

Symonds, M. R. and Moussalli, A. 2011. A brief guide to model selection, multimodel inference and model averaging in behavioural ecology using Akaike's information criterion. -Behav. Ecol. Sociobiol., 65: 13-21.

Temple-Smith, P. D. M. 1969. Some aspects of the biology of the Spur-winged Plover (Vanellus miles novehollandiae, Stephens, 1819). B.Sc. Honours thesis, University of Tasmania, Tasmania.

ten Thoren, A. and Bergmann, H.-H. 1987a. Die Entwicklung der Lautäußerungen bei der Graugans (Anser anser). - J. Ornithol., 128: 181-207.

ten Thoren, B. \& H.-H. Bergmann. 1987b. Veränderung und Konstanz von Merkmalen in der Jugendlichen Stimmentwicklung der Nonnengans (Branta leucopsis). Behaviour, 100: 61-91.

Thomas, D. G. 1969. Breeding biology of the Australian Spur-Winged Plover. -Emu, 69: $81-102$.

Tikhonov, A. V. 1986. Acoustic signalization and ecology of birds [in Russian].- Moscow University Press, Moscow, USSR. 
Volodin, I. A., Volodina, E. V., Klenova, A. V. and Matrosova, V. A. 2015. Gender identification using acoustic analysis in birds without external sexual dimorphism. -Avian Res., 6: 20.

Wheatcroft, D. 2015. Repetition rate of calls used in multiple contexts communicates presence of predators to nestlings and adult birds. -Anim. Behav., 103: 35-44.

Wickham H. 2016. ggplot2: Elegant graphics for data analysis. Springer-Verlag New York. https://ggplot2.tidyverse.org.

Würdinger, I. 1970. Erzeugung, Ontogenie und Funktion der Lautäußerungen bei vier Gänsearten: (Anser indicus, A. caerulescens, A. albifrons und Branta canadensis). -Z. Tierpsychol., 27: 257-302.

Zvonov, B. M. 2011. Ways of developing acoustic signals in birds. -Biol. Bull. Rev., 1: $552-559$. 


\section{SUPPORTING INFORMATION}

Additional supporting information may be found online in the Supporting Information section at the end of the article.

Supplemental Methods - Acoustic Analysis Details of the quantification of acoustic variables

Figure S1. Figure demonstrating methods for calculating frequency modulation for Masked Lapwing

Figure S2. Histogram showing the frequency distribution of log-transformed frequency modulation for Masked Lapwing chick calls

Figure S3. Spectrogram displaying distress calls of five different Red-capped Plover, and Masked Lapwing chicks

Table S1. Body measurements for all Red-capped Plover chicks

Table S2. Body measurements for all Masked Lapwing chicks

Table S3. Results of the generalised linear mixed model investigating the relationship between frequency modulation of lapwing calls with outliers removed and body mass and sex

Table S4. Results of the generalised linear mixed model investigating the relationship of body mass, sex, and call saturation on call entropy for both species 

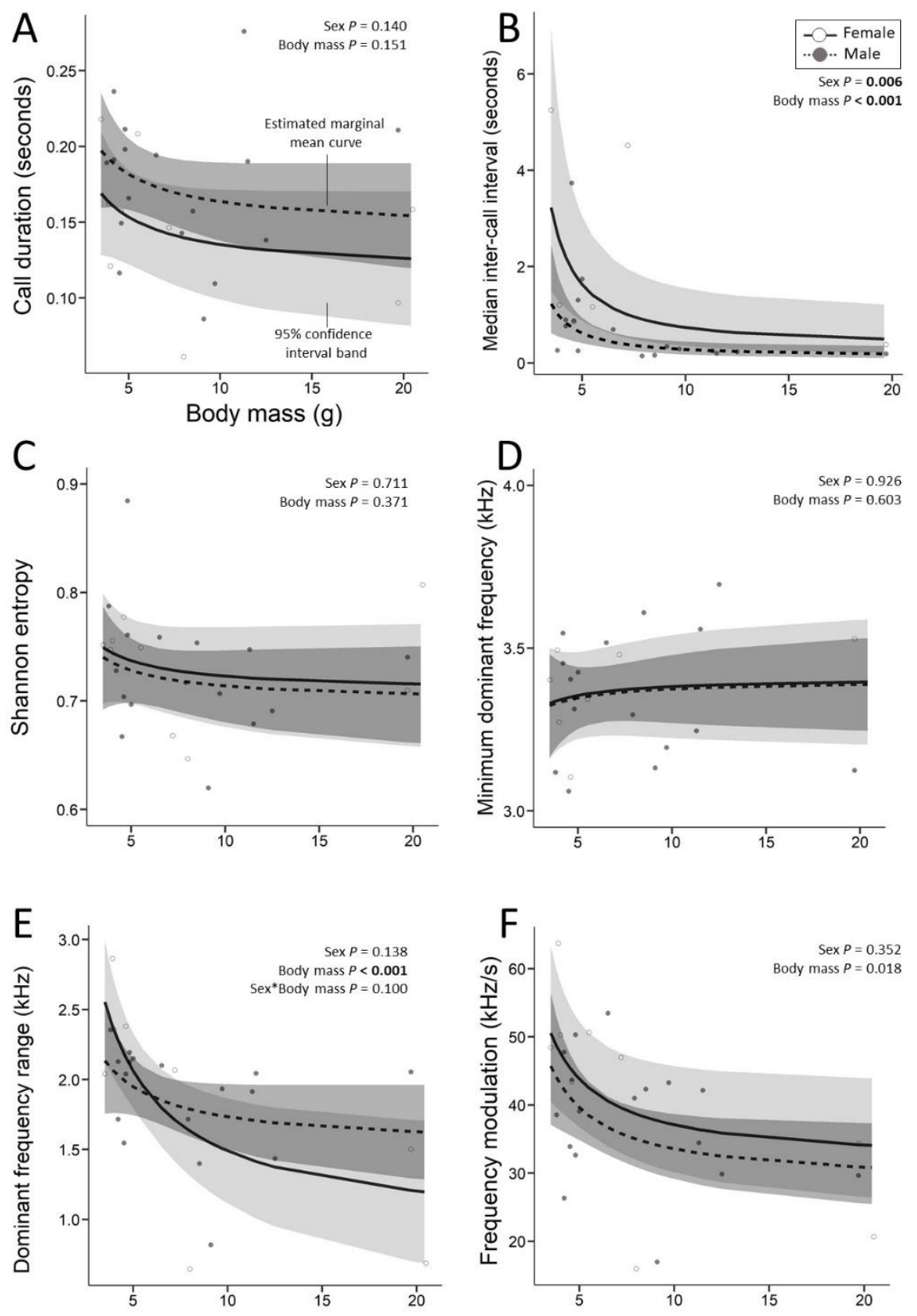

Figure 1. For plovers, call duration did not vary with body mass or sex $(A)$, but inter-call intervals (ICls) decreased with increasing body mass and were shorter in males (B). Entropy and minimum dominant frequency did not vary with body mass or sex (C-D). Dominant frequency range decreased with increasing body mass $(\mathrm{E})$, but frequency modulation did not vary with body mass or sex $(F)$. Estimated marginal means (hatched and solid lines) and 95\% confidence intervals (grey shading) are shown. 

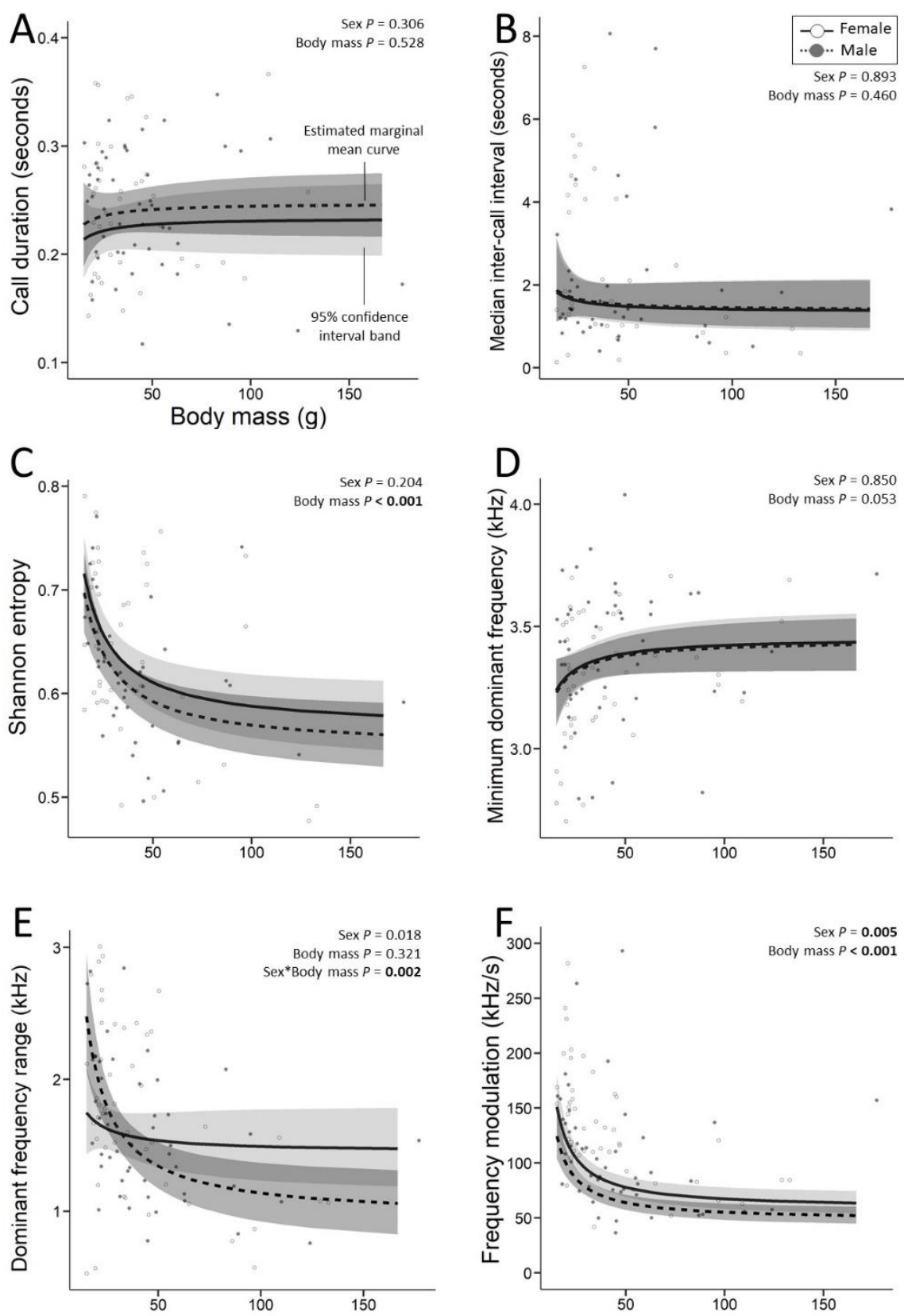

Figure 2. For lapwings, call duration, and inter-call intervals (ICls) did not vary with body mass or sex (A-B), but entropy decreased with increasing body mass (C). Minimum dominant frequency did not vary with body mass or sex (D) but, for lapwings, dominant frequency range decreased with body mass and the decline was greater in males (E). Frequency modulation decreased with body mass and was lower in males $(F)$. Estimated 
bioRxiv preprint doi: https://doi.org/10.1101/2021.12.30.474581; this version posted January $1,2022$. The copyright holder for this preprint

(which was not certified by peer review) is the author/funder, who has granted bioRxiv a license to display the preprint in perpetuity. It is made available under aCC-BY-NC-ND 4.0 International license.

marginal means (hatched and solid lines) and 95\% confidence intervals (grey shading) are shown. 
1 Table 1. Results of separate generalised linear mixed models investigating possible relationships between body mass

2 (reciprocal transformation) and sex (the interaction was selected for inclusion for the frequency range model only) with call

3 duration, inter-call interval $(\mathrm{ICl})$, entropy, minimum frequency, frequency range, and frequency modulation for plovers and

4 lapwings. Chick identity nested within brood identity was included as a random effect for all analyses. We specified a Toeplitz

5 covariance structure for all models. The reference category for sex was female. Estimates are presented as estimates of

6 coefficients \pm standard error for fixed effects, and variance \pm standard deviation for the random effect of identification nested

7 within brood identity. The probability distribution was Gaussian and we used an identity link function for all variables except

8 frequency modulation (plovers), for which we used a negative binomial (linear parameterisation) distribution with a log link.

$9^{*}=$ logarithmically transformed data. ${ }^{* *}=$ to aid interpretation, note that the reciprocal transformation reflects the sign of

10 coefficients.

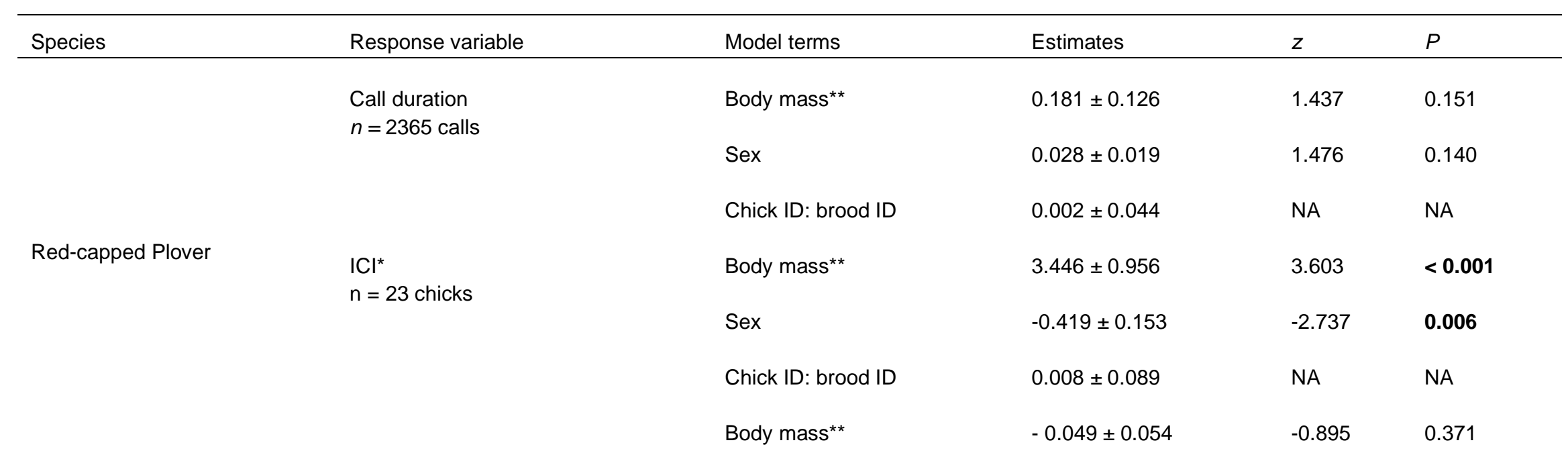




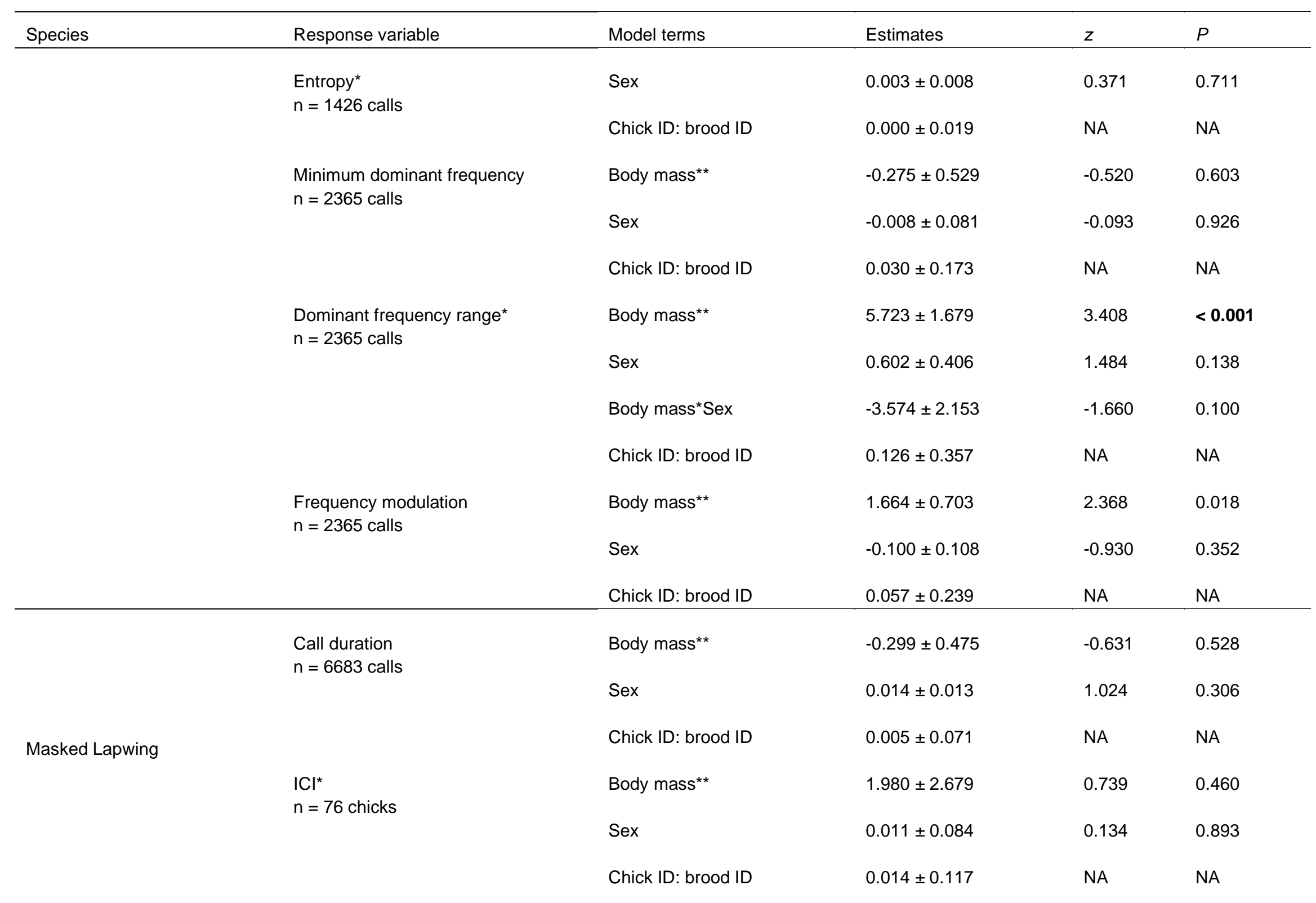




\begin{tabular}{|c|c|c|c|c|c|}
\hline \multirow[t]{2}{*}{ Species } & Response variable & Model terms & Estimates & $z$ & $P$ \\
\hline & $\begin{array}{l}\text { Entropy } \\
\mathrm{n}=3096 \text { calls }\end{array}$ & Body mass ${ }^{\star *}$ & $2.283 \pm 0.476$ & 4.795 & $<0.001$ \\
\hline & & Chick ID: brood ID & $0.004 \pm 0.061$ & NA & NA \\
\hline & $\begin{array}{l}\text { Minimum dominant frequency } \\
n=6683 \text { calls }\end{array}$ & Body mass ${ }^{\star *}$ & $-3.269 \pm 1.688$ & -1.940 & 0.053 \\
\hline & & Chick ID: brood ID & $0.061 \pm 0.248$ & NA & NA \\
\hline & $\begin{array}{l}\text { Dominant frequency range* } \\
\mathrm{n}=6683 \text { calls }\end{array}$ & Body mass ${ }^{* *}$ & $0.548 \pm 0.556$ & 0.986 & 0.324 \\
\hline & & Sex & $-0.069 \pm 0.030$ & -2.361 & 0.018 \\
\hline & $\begin{array}{l}\text { Frequency modulation } \\
n=6619 \text { calls }\end{array}$ & Body mass ${ }^{* *}$ & $6.145 \pm 0.951$ & 6.46 & $<0.001$ \\
\hline & & Sex & $-0.084 \pm 0.030$ & -2.810 & 0.005 \\
\hline & & Chick ID: brood ID & $0.016 \pm 0.126$ & NA & NA \\
\hline
\end{tabular}

11 


\section{3}

\section{SUPPORTING INFORMATION}

\section{Supplemental Methods - Acoustic Analysis Using Raven Pro 1.6.1}

(www.birds.cornell.edu/raven), we viewed each recording as a waveform and spectrogram (plover, fast Fourier transform (FFT) size = 512 samples; lapwing, FFT size $=1024$ samples; hamming window and $87.5 \%$ overlap for both species). Frequency modulation was rapid in many plover calls, so we specified a shorter FFT window for that species to resolve frequency changes better; this was not necessary for lapwing calls, which featured little frequency modulation (Fig. S3; definition below). Using spectrograms as guides, we manually marked the approximate beginning and end of every call of each chick (or its identifiable sibling) on the waveform. Using these time records, we then opened each call in $\mathrm{R}$ ( $\mathrm{R}$ Core Team 2021), plus $30 \mathrm{~ms}$ before and after the call, using the seewave and tuneR packages (Sueur et al. 2008, Ligges et al. 2018). We applied a $1000 \mathrm{~Hz}$ high-pass filter, which reduced low-frequency background noise without affecting call structure, and normalised calls to $0 \mathrm{~dB}$. For lapwing calls, we adjusted the start and end times using a more objective approach based on an amplitude threshold, which defined the start of calls as the point where amplitude exceeded $15 \%$ of the maximum amplitude for $2 \mathrm{~ms}$ and the end of calls as the point where amplitude fell below $15 \%$ for 2 ms. We plotted the new start and end times on waveforms and spectrograms (settings as above) to ensure that values derived from the amplitude threshold approach were not based on artifacts. In a few cases (40 of 6835 calls), high background noise masked the start and end times, so we relied on our original (manually determined) times for those 
calls. For plover calls, low signal-to-noise ratios precluded the use of the amplitude threshold approach in many calls, so we used the manually selected start and end times.

We divided each call into a series of contiguous 2.9-ms time bins, and, for each bin, measured the Shannon spectral entropy and dominant frequency from a mean power spectrum (settings as per the corresponding spectrogram listed above). Entropy is a measure of tonal purity that approaches 0 for pure tones and 1 for white noise, and dominant frequency is the frequency of maximum amplitude, excluding harmonics and background noises. We validated our measures of dominant frequency by plotting them against time and comparing the resulting plot to the corresponding spectrogram (Fig. S1). In some cases, measures of dominant frequency, particularly at the start or end of the

call, were based on background noise rather than the call itself. If these measurement errors were limited to one or two time bins (i.e. 2.9 or $5.8 \mathrm{~ms}$ ), we excluded those bins from subsequent analyses; if they occurred in more than two time bins, or in the middle of the call, we excluded the entire call from subsequent analyses (we thereby excluded 235 of 2600 plover calls, and 153 of 6835 lapwing calls).

\section{References}

50 Ligges, U., Krey, S., Mersmann, O. and Schnackenberg, S. 2018. TuneR: Analysis of music and speech. https://CRAN.R-project.org/package=tuneR

52 R Core Team 2021. R: A language and environment for statistical computing. $R$ Foundation for Statistical Computing, Vienna. https://www.R-project.org/

54 Sueur, J., Aubin T. and Simonis C. 2008. Seewave: A free modular tool for sound analysis and synthesis. -Bioacoustics, 18: 213-226 
bioRxiv preprint doi: https://doi.org/10.1101/2021.12.30.474581; this version posted January 1,2022. The copyright holder for this preprint (which was not certified by peer review) is the author/funder, who has granted bioRxiv a license to display the preprint in perpetuity. It is made available under aCC-BY-NC-ND 4.0 International license.

56
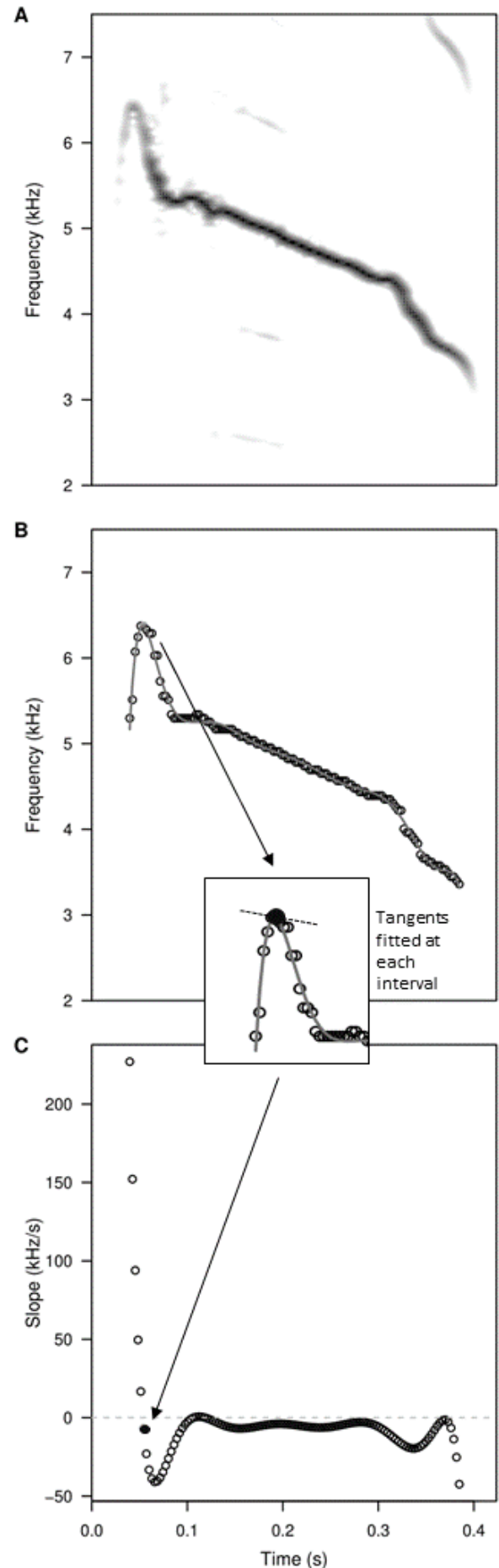
58 Figure S1. To quantify the structure of Masked lapwing calls we first inspected the

59 spectrogram of each call (A). Calls were then divided into contiguous 2.9-ms time bins, 60 and a mean power spectrum calculated for each bin. We measured the dominant

61 frequency of each bin from the corresponding mean spectrum and plotted it as a function

62 of time (B; open circles). We regressed dominant frequency values on time using a series

63 of polynomial regressions (first to twelfth order), and superimposed the best-fitting 64 regression on the dominant frequency values (solid line; B). We calculated the slope of 65 the tangent to the selected polynomial for every 2.9-ms interval and plotted it as a function 66 of time (open circles; C). The inset shows an example of a tangent (solid circle and 67 hatched line), for the 2.9-ms interval marked in other panels ( $B$ and $C$ ) by a solid black 68 circle. We used the range in slopes to characterise the magnitude of frequency 69 modulation throughout the call. The grey hatched line indicates a slope of zero (C). 




72 Figure S2. The frequency distribution of log-transformed frequency modulation (rate of

73 change in dominant frequency) for lapwing chick calls.

74 

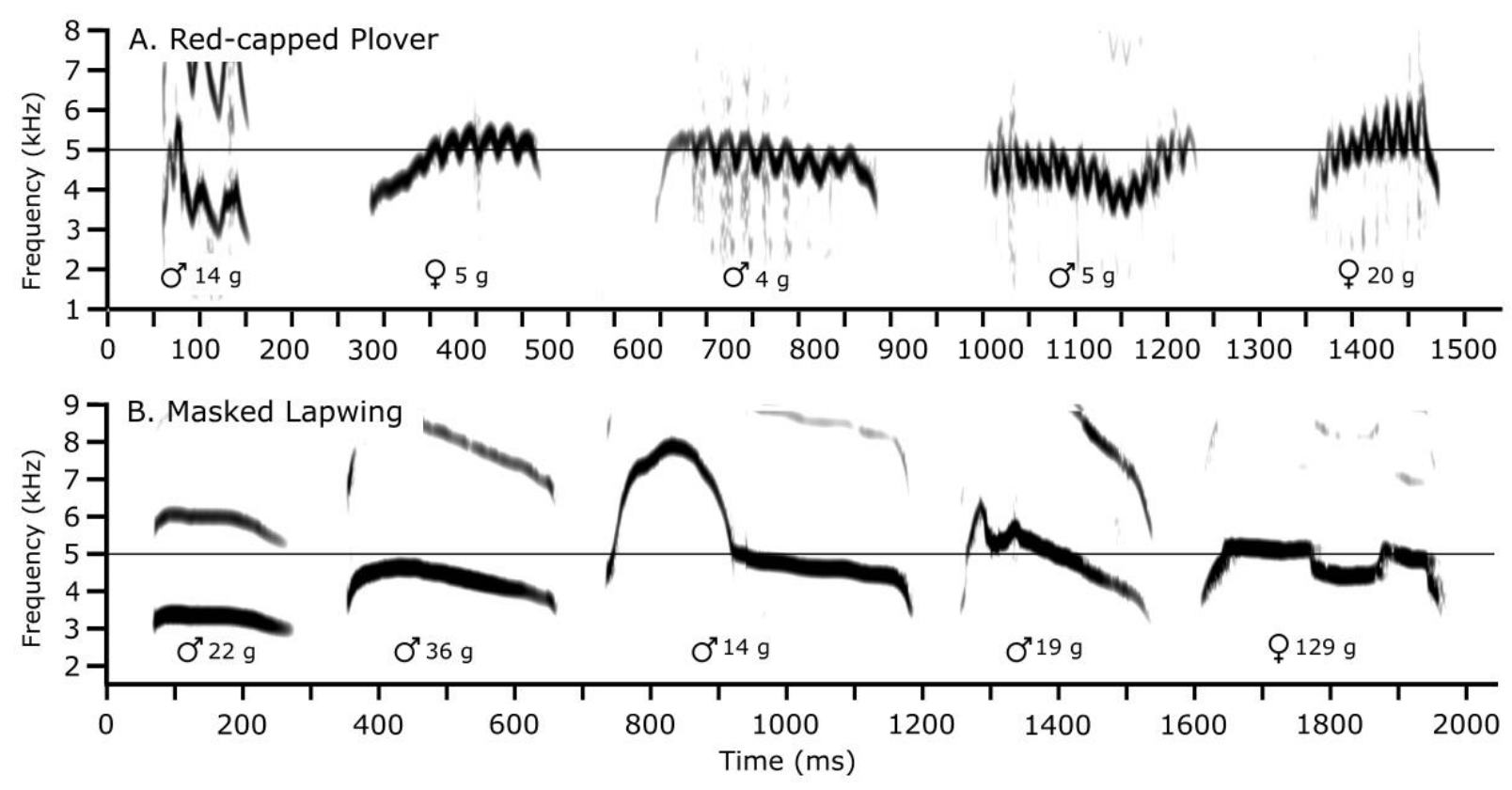

Figure S3. Chick distress calls differed substantially between Red-capped Plover (A) and

78 Masked Lapwing (B), particularly in the presence and extent of frequency modulation

79 (FM). Calls are ordered left-to-right by rate of FM for plovers and by increasing overall

80 complexity for lapwings.

81 
Table S1. Body measurements for all Red-capped Plover chicks within this study.

\begin{tabular}{|c|c|c|c|c|c|c|c|c|c|c|c|}
\hline Date & Known age & Recording number & Chick ID & Sex & Brood number & Body mass & Head bill & Bill & Tarsus & Tarsus and toe & Recapture \\
\hline $3 / 01 / 2019$ & 1.0 & R350 & chick 2 & male & 1 & 4.5 & 22.6 & 17.6 & 19.42 & 33 & \\
\hline 20/01/2019 & & R362 & chick $2 a$ & female & 3 & 4 & 24.12 & 7.6 & 19.02 & 34.5 & \\
\hline $1 / 02 / 2019$ & & R379 & 3691822 & male & 4 & 11.3 & 29.43 & 10.78 & 22.35 & 40 & \\
\hline $1 / 02 / 2019$ & & $R 380+381$ & 3691823 & male & 5 & 8.5 & 29.41 & 10.62 & 23.96 & 41 & \\
\hline 4/03/2019 & & Z240 & 3691820 & male & 18 & 6.3 & 25.9 & 8.09 & 19.66 & 38 & \\
\hline $1 / 02 / 2019$ & 1.0 & R382 & 3691824 & female & 6 & 5.5 & 24.2 & 7.59 & 16.35 & 35 & \\
\hline 22/03/2019 & & R410 & 3691820 & male & 18 & 14.5 & 32.64 & 9.83 & 23.55 & 42 & Y \\
\hline $1 / 02 / 2019$ & 1.0 & R383 & 3691825 & female & 6 & 3.5 & 24.89 & 8.16 & 18.62 & 35 & \\
\hline $11 / 02 / 2019$ & 1.0 & R391 & 3691827 & male & 8 & 5 & 20.71 & 6.25 & 16.5 & 31 & \\
\hline $11 / 02 / 2019$ & & R394 & 3691835 & male & 11 & 4.2 & 23.89 & 7.82 & 17.8 & 34 & \\
\hline $11 / 02 / 2019$ & & R393 & 3691829 & male & 9 & 19.7 & 35.24 & 12 & 24.98 & 45 & \\
\hline $18 / 02 / 2019$ & & Z232 & 3691831 & female & 14 & 8 & 27.59 & 9.3 & 20 & 40 & \\
\hline $11 / 02 / 2019$ & & R392 & 3691828 & male & 12 & 5.1 & 23.37 & 7.31 & 18.65 & 36 & \\
\hline 18/02/2019 & & $Z 233+Z 234$ & 3691832 & female & 14 & 20.5 & 35.7 & 12.88 & 26.02 & 44.5 & \\
\hline $4 / 03 / 2019$ & & Z238 & 3691828 & male & 12 & 21.8 & 33.73 & 10.91 & 24.99 & 45 & Y \\
\hline 18/02/2019 & & $Z 230+Z 231$ & 3691833 & female & 13 & 19.7 & 35.13 & 11.31 & 25.42 & 42.5 & \\
\hline 18/02/2019 & & Z229 & 3691834 & female & 12 & 7.2 & 26.52 & 8.5 & 20.75 & 38.5 & Y \\
\hline 18/02/2019 & & Z235 & 3691836 & male & 15 & 11.5 & 29.96 & 10.1 & 20.44 & 39.5 & \\
\hline $11 / 02 / 2019$ & & R396 & 3691834 & female & 12 & 5.3 & 23.68 & 7.3 & 19.3 & 46 & \\
\hline 25/02/2019 & & Z236 & 3691828 & male & 12 & 12.5 & 30.51 & 9.61 & 21.79 & 41 & $Y$ \\
\hline 4/03/2019 & & Z239 & 3693837 & male & 17 & 7.9 & 26.88 & 8.79 & 22.6 & 42 & \\
\hline 8/03/2019 & 1.0 & R405 & 3691839 & male & 19 & 3.8 & 23.83 & 7.74 & 19.15 & 46 & \\
\hline 8/03/2019 & 1.0 & R404 & 3691838 & male & 19 & 3.6 & 25.24 & 7.55 & 18.88 & 36 & \\
\hline 8/03/2019 & & R406 & 3691840 & male & 18 & 9.7 & 27.34 & 8.85 & 19.98 & 38 & Y \\
\hline $14 / 03 / 2019$ & & R407 & 3691820 & male & 18 & 9.1 & 29.14 & 10.8 & 20.46 & 39.5 & Y \\
\hline $14 / 03 / 2019$ & & R408 & 3691840 & male & 18 & 8.2 & 29.23 & 9.19 & 21.67 & 44 & Y \\
\hline $14 / 03 / 2019$ & 7.0 & R409 & 3691838 & male & 19 & 4.8 & 26.7 & 8.15 & 19.15 & 37 & $Y$ \\
\hline 22/03/2019 & & R411 & 3691840 & male & 18 & 14.8 & 31.85 & 11.07 & 22.04 & 41 & $Y$ \\
\hline
\end{tabular}




\begin{tabular}{|c|c|c|c|c|c|c|c|c|c|c|c|}
\hline Date & Known age & Recording number & Chick ID & Sex & Brood number & Body mass & Head bill & Bill & Tarsus & Tarsus and toe & Recapture \\
\hline $16 / 12 / 2019$ & 1.0 & Z255 & 03691814 & male & 24 & 4.6 & 21.79 & 7.1 & 16.51 & 33 & \\
\hline $16 / 12 / 2019$ & 1.0 & Z254 & 03691815 & female & 23 & 4.6 & 22.05 & 7.02 & 17.34 & 33 & \\
\hline $16 / 12 / 2019$ & 1.0 & Z252 & 03691817 & male & 22 & 6.5 & 24.22 & 7.65 & 17.92 & 34.5 & \\
\hline $16 / 12 / 2019$ & 1.0 & Z251 & 03691818 & female & 22 & 3.9 & 23.35 & 7.78 & 17.42 & 35 & \\
\hline $16 / 12 / 2019$ & 1.0 & Z247 & 03691845 & male & 20 & 4.8 & 22.98 & 17.94 & 16.83 & 34 & \\
\hline $16 / 12 / 2019$ & 1.0 & $\mathrm{Z} 250$ & 03691846 & male & 21 & 4.2 & 23.3 & 7.52 & 18.3 & 36 & \\
\hline $16 / 12 / 2019$ & & Z247 & 03691845 & male & 20 & 4.8 & 22.98 & 17.94 & 16.83 & 34 & \\
\hline $16 / 12 / 2019$ & & Z250 & 03691846 & male & 21 & 4.2 & 23.3 & 7.52 & 18.3 & 36 & \\
\hline $16 / 12 / 2019$ & & Z251 & 03691818 & female & 22 & 3.9 & 23.35 & 7.78 & 17.42 & 35 & \\
\hline $16 / 12 / 2019$ & & Z252 & 03691817 & male & 22 & 6.5 & 24.22 & 7.65 & 17.92 & 34.5 & \\
\hline $16 / 12 / 2019$ & & Z254 & 03691815 & female & 23 & 4.6 & 22.05 & 7.02 & 17.34 & 33 & \\
\hline $16 / 12 / 2019$ & & Z255 & 03691814 & male & 24 & 4.6 & 21.79 & 7.1 & 16.51 & 33 & \\
\hline
\end{tabular}


Table S2. Body measurements for all Masked Lapwing chicks within this study.

\begin{tabular}{|c|c|c|c|c|c|c|c|c|c|c|}
\hline Date & Known age & Recording number & Chick ID & Sex & Brood number & Body mass & Head bill & Bill & Tarsus & Tarsus and toe \\
\hline $2 / 08 / 2018$ & 1.0 & $\mathrm{R} 63+\mathrm{R} 64+\mathrm{Z} 71$ & 083- 24303 & male & 1 & 18.2 & 37.7 & 11.89 & 27.51 & 59 \\
\hline 2/08/2018 & 1.0 & R65 & 083- 24304 & male & 1 & 22.4 & 36 & 12.32 & 32.19 & 57.1 \\
\hline $2 / 08 / 2018$ & 1.0 & R66 & 083- 24305 & female & 1 & 22.5 & 35.41 & 12.01 & 31.09 & 58 \\
\hline 2/08/2018 & 1.0 & R67 & 083- 24306 & male & 2 & 22.4 & 35.09 & 11.02 & 28.76 & 55.5 \\
\hline 2/08/2018 & 1.0 & R68 & 083- 24307 & female & 2 & 21.1 & 36.07 & 11.31 & 30.33 & 59 \\
\hline $2 / 08 / 2018$ & 1.0 & R69 & 083- 24308 & female & 2 & 22.2 & 35.6 & 11.65 & 28.99 & 58 \\
\hline 2/08/2018 & 1.0 & R71 & $083-24310$ & male & 3 & 17 & 32.17 & 9.8 & 27.82 & 52 \\
\hline 3/08/2018 & 1.0 & $\mathrm{R} 72$ & 083- 24311 & male & 4 & 21.5 & 33.2 & 10.47 & 28.3 & 55.5 \\
\hline $3 / 08 / 2018$ & & R76 & 083- 24312 & female & 5 & 45.4 & 47.29 & 19.21 & 33.49 & 64 \\
\hline $3 / 08 / 2018$ & 2.0 & $\mathrm{R} 84$ & 083- 24313 & female & 6 & 21.8 & 37.98 & 13.79 & 21.15 & 59.5 \\
\hline 3/08/2018 & 2.0 & $\mathrm{R} 78+\mathrm{R} 81$ & 083- 24314 & male & 6 & 19.4 & 37.92 & 14.01 & 30.26 & 60 \\
\hline 3/08/2018 & 2.0 & R83 & 083- 24315 & female & 6 & 20.7 & 37.06 & 13.8 & 29.84 & 58 \\
\hline 3/08/2018 & 2.0 & $R 79+R 80+R 82$ & 083- 24316 & male & 6 & 19.5 & 36.81 & 12.95 & 29.64 & 59 \\
\hline $3 / 08 / 2018$ & & R85 & 083- 24317 & female & 7 & 23.9 & 42.95 & 16.42 & 29.66 & 60 \\
\hline 3/08/2018 & & $\mathrm{R} 86$ & 083- 24318 & female & 7 & 23.1 & 41.6 & 15 & 30 & 59 \\
\hline $3 / 08 / 2018$ & & R87 & 083- 24319 & male & 9 & 28 & 44.43 & 17.45 & 34.02 & 65 \\
\hline $3 / 08 / 2018$ & & R88 & 083- 24320 & female & 9 & 29 & 44.06 & 18.66 & 32.88 & 64 \\
\hline $3 / 08 / 2018$ & & R89 & 083- 24321 & female & 10 & 22.5 & 35.52 & 12.44 & 28.89 & 58 \\
\hline $3 / 08 / 2018$ & 2.0 & R90 & 083- 24322 & female & 11 & 22.5 & 34.49 & 10.58 & 28.6 & 58 \\
\hline $3 / 08 / 2018$ & 2.0 & R91 & 083- 24323 & male & 11 & 21.5 & 36.6 & 11.91 & 31.11 & 60.5 \\
\hline $3 / 08 / 2018$ & & $\mathrm{R} 93+\mathrm{R} 94$ & 083- 24325 & male & 12 & 95 & 55.09 & 22.79 & 44.94 & 80 \\
\hline $3 / 08 / 2018$ & 7 or 8 & $R 96+R 100$ & 083- 24326 & male & 13 & 22.3 & 41.09 & 15.3 & 31.74 & 63 \\
\hline $3 / 08 / 2018$ & 7 or 8 & R $97+R 99$ & 083- 24327 & male & 13 & 25.2 & 40.75 & 13.99 & 32.08 & 61 \\
\hline $3 / 08 / 2018$ & 7 or 8 & R98 & 083- 24328 & male & 13 & 17.9 & 41.69 & 15.6 & 32.14 & 60.5 \\
\hline $3 / 08 / 2018$ & 7 or 8 & R101 & 083- 24329 & female & 13 & 26.5 & 42.09 & 14.9 & 32.21 & 60 \\
\hline $3 / 08 / 2018$ & 10 or 11 & R102 & $083-24330$ & female & 14 & 37.4 & 46.45 & 17.85 & 36.6 & 68 \\
\hline 3/08/2018 & 10 or 11 & $\mathrm{R} 103+\mathrm{R} 106$ & 083- 24331 & male & 14 & 33.4 & 42.91 & 13.83 & 32.84 & 62 \\
\hline $3 / 08 / 2018$ & 10 or 11 & R104 & 083- 24332 & female & 14 & 46.8 & 47.42 & 17.15 & 37.28 & 69.5 \\
\hline $3 / 08 / 2018$ & 10 or 11 & R105 & 083- 24333 & male & 14 & 44.9 & 47.3 & 17.48 & $N / A$ & 68 \\
\hline
\end{tabular}




\begin{tabular}{|c|c|c|c|c|c|c|c|c|c|c|}
\hline Date & Known age & Recording number & Chick ID & Sex & Brood number & Body mass & Head bill & Bill & Tarsus & Tarsus and toe \\
\hline $6 / 08 / 2020$ & 5 or 6 & $\mathrm{R} 107$ & chick 1d & male & 16 & 15.5 & 36.35 & 12.51 & 28.19 & 53 \\
\hline 9/08/2018 & & $\mathrm{R} 118$ & 083- 24338 & male & 17 & 63 & 51 & 21.58 & 39.18 & 72 \\
\hline $9 / 08 / 2018$ & & $R 119+R 121$ & 083- 24339 & female & 17 & 73 & 52.75 & 22.67 & 43.7 & 76 \\
\hline 9/08/2018 & & $\mathrm{R} 120$ & 083- 24340 & female & 17 & 65 & 52.91 & 23.76 & 40.65 & 73 \\
\hline $9 / 08 / 2018$ & & $\mathrm{R} 123$ & 083- 24341 & female & 18 & 18.6 & 37.19 & 12.85 & 29.97 & 59 \\
\hline $9 / 08 / 2018$ & & $\mathrm{R} 126$ & 083- 24342 & female & 18 & 20.7 & 37.43 & 12.39 & 31.69 & 58 \\
\hline $9 / 08 / 2018$ & & $R 132+R 133$ & 083- 24345 & female & 19 & 24.3 & 37.9 & 13.8 & 31.79 & 62 \\
\hline $9 / 08 / 2018$ & & $\mathrm{R} 134$ & 083- 24346 & male & 19 & 21.1 & 37.33 & 12.53 & 31.19 & 58 \\
\hline $9 / 08 / 2018$ & & $\mathrm{R} 140$ & 083- 24348 & female & 20 & 44.6 & 48.4 & 17 & 37.52 & 69 \\
\hline $9 / 08 / 2018$ & & $\mathrm{R} 143$ & 083- 24350 & female & 20 & 39.55 & 46.72 & 17.33 & 34.26 & 68 \\
\hline 9/08/2018 & 3.0 & $\mathrm{R} 145$ & 083-36151 & female & 21 & 23 & 39.11 & 14.67 & 34 & 62 \\
\hline $9 / 08 / 2018$ & 3.0 & $\mathrm{R} 146$ & 083-36152 & female & 21 & 21.2 & 37.46 & 13.14 & 31.47 & 59.5 \\
\hline $9 / 08 / 2018$ & & $\mathrm{R} 147$ & 083-36153 & male & 22 & 37 & 46.26 & 17.93 & 34.59 & 64 \\
\hline 9/08/2018 & & $\mathrm{R} 148$ & 083-36154 & male & 22 & 36.2 & 45 & 18.89 & 34.29 & 63 \\
\hline $9 / 08 / 2018$ & & R149 & 083-36155 & female & 22 & 34 & 44.79 & 18.35 & 35.83 & 63 \\
\hline 10/08/2018 & 1 to 3 & $\mathrm{R} 154$ & 083-36158 & female & 24 & 21.2 & 35.81 & 11.39 & 31 & 59 \\
\hline 10/08/2018 & 1 to 3 & R157 R158 & 083-36159 & male & 24 & 19.5 & 37.45 & 12.4 & 29.66 & 56.5 \\
\hline 10/08/2018 & 1 to 3 & R159 & 083-36160 & female & 24 & 20.1 & 34.65 & 10.68 & 30.22 & 56 \\
\hline 10/08/2018 & & $\mathrm{R} 160$ & 083-36161 & female & 25 & 19.4 & 38.43 & 14.25 & 32.69 & 61.5 \\
\hline 10/08/2018 & & $\mathrm{R} 161$ & 083-36162 & male & 25 & 18.5 & 38.31 & 14.71 & 30.04 & 58 \\
\hline 10/08/2018 & & $\mathrm{R} 162$ & 083-36163 & female & 25 & 15.2 & 39.83 & 15.28 & 34.69 & 63.5 \\
\hline 16/08/2018 & & $R 194+195$ & chick 1 & male & 27 & 55 & 50.62 & 22.55 & 42.15 & 75 \\
\hline 16/08/2018 & & $\mathrm{R} 194$ & chick 2 & female & 27 & 53.9 & 48.25 & 19.5 & 39.3 & 70 \\
\hline 23/08/2018 & & $R 208+209$ & 083-36166 & male & 29 & 43.5 & 45.68 & 16.62 & 35.89 & 65 \\
\hline 23/08/2018 & & $\mathrm{R} 210$ & 083-36167 & male & 29 & 49 & 46.96 & 19.24 & 36 & 63.5 \\
\hline 23/08/2018 & & $\mathrm{R} 211$ & 083-36168 & female & 30 & 97 & 54.49 & 21.15 & 47.35 & 81 \\
\hline 23/08/2018 & & $\mathrm{R} 212$ & 083-36169 & female & 30 & 97 & 53.81 & 21.3 & 46.83 & 80 \\
\hline 23/08/2018 & & $\mathrm{R} 213$ & 083-36170 & male & 31 & 36 & 43.25 & 15.61 & 33.59 & 62 \\
\hline 23/08/2018 & & $\mathrm{R} 214$ & 083-36171 & male & 32 & 87 & 54.79 & 24.55 & 44.7 & 80 \\
\hline 23/08/2018 & & $\mathrm{R} 215$ & 083-36172 & female & 33 & 30.3 & 42.46 & 15 & 34.45 & 61 \\
\hline 23/08/2018 & & $\mathrm{R} 216$ & 083-36174 & male & 33 & 26.5 & 41.19 & 15 & 33.6 & 62 \\
\hline 23/08/2018 & & $\mathrm{R} 217$ & 083-36175 & female & 33 & 33.5 & 42.46 & 15.78 & 35.01 & 64 \\
\hline
\end{tabular}




\begin{tabular}{|c|c|c|c|c|c|c|c|c|c|c|}
\hline Date & Known age & Recording number & Chick ID & Sex & Brood number & Body mass & Head bill & Bill & Tarsus & Tarsus and toe \\
\hline $23 / 08 / 2018$ & 3.0 & $\mathrm{R} 221$ & $083-36177$ & female & 34 & 18.5 & 37.69 & 12.2 & 29.48 & 58 \\
\hline 23/08/2018 & 3.0 & $\mathrm{R} 222$ & 083-36178 & female & 34 & 20.2 & 38.2 & 13.05 & 30 & 57 \\
\hline $23 / 08 / 2018$ & 10.0 & $\mathrm{R} 223$ & 083-36179 & male & 35 & 25.5 & 40.26 & 15.29 & 31.45 & 57 \\
\hline 23/08/2018 & 10.0 & $\mathrm{R} 224$ & 083-36180 & male & 35 & 35.3 & 44.81 & 17.4 & 33.7 & 64.5 \\
\hline $24 / 08 / 2018$ & & $\mathrm{R} 228$ & $083-36181$ & male & 36 & 58.8 & 48.97 & 19.39 & 38.07 & 71 \\
\hline $24 / 08 / 2018$ & & $\mathrm{R} 229$ & 083-36182 & female & 36 & 109 & 59.14 & 26.58 & 48.16 & 85 \\
\hline $24 / 08 / 2018$ & & $\mathrm{R} 230$ & 083-36183 & male & 36 & 110 & 58.08 & 25.71 & 49.65 & 83.5 \\
\hline 24/08/2018 & 14.0 & $\mathrm{R} 231$ & 083-36184 & male & 37 & 56.1 & 47.83 & 17.49 & 37.34 & 68.5 \\
\hline $24 / 08 / 2018$ & & $\mathrm{R} 232$ & 083-36185 & male & 38 & 83 & 53.84 & 22.21 & 35 & 80 \\
\hline $24 / 08 / 2018$ & & $\mathrm{R} 233$ & 083-36186 & female & 38 & 47 & 48.78 & 20.5 & 34.85 & 65 \\
\hline $12 / 09 / 2018$ & 13 to 14 & $\mathrm{R} 318$ & chick 1a & female & 39 & 41.8 & 46.3 & 17.92 & 35.11 & 67 \\
\hline $12 / 09 / 2018$ & & R321 & chick 1b & female & 41 & 29 & 41.3 & 15.75 & 32.68 & 59 \\
\hline $12 / 09 / 2018$ & & R322 & chick 1c & male & 42 & 30 & 43.21 & 18.42 & 34.49 & 62 \\
\hline $12 / 09 / 2018$ & & $\mathrm{R} 323$ & chick $2 a$ & male & 42 & 24.5 & 42.37 & 15.76 & 33.8 & 61.5 \\
\hline $20 / 09 / 2018$ & & T56 & 083-36188 & female & 44 & 35 & 42.81 & 16.81 & 32.84 & 61 \\
\hline $20 / 09 / 2018$ & & T57 & 083-36189 & female & 44 & 28.7 & 42.02 & 17.3 & 22.33 & 61.5 \\
\hline $20 / 09 / 2018$ & & T58 & 083-36190 & male & 45 & 32.5 & 45 & 18.35 & 32.19 & 61 \\
\hline 20/09/2018 & & $\mathrm{T} 59+60$ & 083-36173 & female & 46 & 44 & 47.41 & 18.72 & 36.13 & 66.5 \\
\hline $20 / 09 / 2018$ & & $\mathrm{~T} 61,62,63+64$ & 083-36191 & male & 46 & 62.8 & 49.7 & 19.38 & 40.22 & 71 \\
\hline $20 / 09 / 2018$ & & T65 & 083-36192 & male & 46 & 41 & 46.18 & 17.04 & 34.79 & 66 \\
\hline $20 / 09 / 2018$ & & T69 & 083-36196 & female & 48 & 50.5 & 46.54 & 17.91 & 36.22 & 64.5 \\
\hline $20 / 09 / 2018$ & & $\mathrm{~T} 67+70$ & 083-36194 & male & 48 & 48.3 & 47.38 & 19.44 & 37.72 & 70 \\
\hline $20 / 09 / 2018$ & & T68 & 083-36195 & male & 48 & 47.6 & 47.63 & 17.76 & 37.49 & 67 \\
\hline $20 / 09 / 2018$ & & T71 & 083-36197 & male & 49 & 177 & 62.84 & 28.29 & 59.84 & 97 \\
\hline $20 / 09 / 2018$ & & T75 & $083-27551$ & female & 50 & 86 & 55.43 & 24.45 & 47.84 & 81.5 \\
\hline $20 / 09 / 2018$ & & T72 & 083-36198 & male & 50 & 55.4 & 49.3 & 20.71 & 39.3 & 69 \\
\hline 20/09/2018 & & T73 & 083-36199 & male & 50 & 89 & 52.61 & 21.25 & 46.68 & 81 \\
\hline $21 / 09 / 2018$ & & T76 & 083-27552 & female & 51 & 129 & 59.96 & 26.75 & 52.12 & 92 \\
\hline $21 / 09 / 2018$ & & T77 & $083-27553$ & male & 51 & 124 & 59.5 & 27.34 & 55.69 & 94 \\
\hline $21 / 09 / 2018$ & & T78 & 083-27554 & male & 52 & 39.7 & 45 & 16.92 & 36.64 & 68 \\
\hline $21 / 09 / 2018$ & & T79 & 083-27555 & male & 53 & 45.2 & 44.58 & 15.5 & 34.99 & 65.5 \\
\hline $21 / 09 / 2018$ & & T81 & 083-27557 & male & 55 & 31.4 & 45.38 & 18.49 & 33.32 & 61 \\
\hline
\end{tabular}




\begin{tabular}{|c|c|c|c|c|c|c|c|c|c|c|}
\hline Date & Known age & Recording number & Chick ID & Sex & Brood number & Body mass & Head bill & Bill & Tarsus & Tarsus and toe \\
\hline $21 / 09 / 2018$ & & T82 & $083-27558$ & male & 56 & 44.9 & 47.5 & 18.54 & 36.98 & 67 \\
\hline 21/09/2018 & & T83 & 083-27559 & female & 57 & 133 & 58.4 & 25.23 & 51.11 & 88 \\
\hline 21/09/2018 & & T84 & $083-27560$ & male & 58 & 49.7 & 45.41 & 18.25 & 35 & 66 \\
\hline
\end{tabular}


87 Table S3. Results of the generalised linear mixed model investigating the relationship

88 between frequency modulation of lapwing calls with outliers removed (> 1.5 times the

89 interquartile ranges below the first or above the third quartile) and body mass (reciprocal

90 transformation) and sex (reference category = female). We specified a Toeplitz

91 covariance structure, and chick identity nested within brood identity was included as the

92 random effect for all analyses. Estimates are presented as estimates of coefficients \pm

93 standard error for fixed effects, and variance \pm standard deviation for the random effect

94 of Identification nested within Brood ID. The probability distribution was Gaussian and we

95 used an identity link. The response variable was logarithmically transformed. * $=$ to aid

96 interpretation, note that the reciprocal transformation reflects the sign of coefficients.

\begin{tabular}{llllll}
\hline Species & Response variable & Model terms & Estimates & $z$ & $P$ \\
\hline \multirow{3}{*}{ Masked Lapwing } & Body mass $^{*}$ & $5.626 \pm 0.873$ & 6.450 & $<\mathbf{0 . 0 0 1}$ \\
& $\begin{array}{l}\text { Frequency modulation } \\
n=6456 \text { calls }\end{array}$ & Sex & $-0.091 \pm 0.027$ & -3.330 & $<\mathbf{0 . 0 0 1}$ \\
& & Identification: Brood ID & $0.014 \pm 0.119$ & NA & NA \\
\hline
\end{tabular}

97 
98 Table S4. Results of the generalised linear mixed model investigating the relationships of

99 body mass (reciprocal transformation), sex (reference category $=$ female), and call

100

101

102

103

104

105

106

interpretation, note that the reciprocal transformation reflects the sign of coefficients.

\begin{tabular}{|c|c|c|c|c|c|}
\hline Species & Response variable & Model terms & Estimates & $z$ & $P$ \\
\hline \multirow{4}{*}{ Red-capped Plover } & \multirow{4}{*}{$\begin{array}{l}\text { Entropy } \\
n=2365 \text { calls }\end{array}$} & Body mass ${ }^{* *}$ & $-0.069 \pm 0.047$ & -1.455 & 0.146 \\
\hline & & Sex & $0.003 \pm 0.007$ & 0.413 & 0.679 \\
\hline & & Saturation & $-0.013 \pm 0.001$ & -16.810 & $<0.001$ \\
\hline & & Identification: Brood ID & $0.000 \pm 0.017$ & NA & NA \\
\hline \multirow{4}{*}{ Masked Lapwing } & \multirow{4}{*}{$\begin{array}{l}\text { Entropy } \\
n=6456 \text { calls }\end{array}$} & Body mass* & $1.810 \pm 0.373$ & 4.850 & $<0.001$ \\
\hline & & Sex & $-0.003 \pm 0.011$ & -0.280 & 0.780 \\
\hline & & Saturation & $-0.020 \pm 0.002$ & -9.610 & $<0.001$ \\
\hline & & Identification: Brood ID & $0.003 \pm 0.055$ & NA & NA \\
\hline
\end{tabular}

